\title{
Social and environmental change in the Arctic: emerging opportunities for well-being transformations through stewardship
}

\author{
F. Stuart Chapin, $I I I^{1}$
}

The Arctic is changing in many dimensions, as described throughout this special feature. Many Arctic changes, such as climate change, mining, and oil extraction, are driven by economic forces that originate largely outside of the Arctic. Others, such as changes in Arctic flora and fauna, Indigenous cultures, and regional economy, are also substantially influenced by decisions made within the Arctic. Recent changes, wherever they occur, often have devastating consequences for local communities and contribute to public despair and disengagement rather than to concerted search for solutions. A new framework is needed to link identification of deep problems with motivation and strategies to seek innovative solutions. Stewardship is one such framework.

I define stewardship as the proactive shaping of social and biophysical changes to support the well-being of both people and nature (Chapin 2020). Stewardship recognizes that the well-being of people and nature are intertwined and interdependent, rather than requiring a choice between people vs. nature. It differs from some conservation approaches by emphasizing active intervention to enhance well-being rather than seeking to prevent potential changes. Stewardship accepts that change creates uncertainty in outcomes, so strategies for well-being must be resilient and responsive to emerging conditions rather than codified and inflexible. Given that many changes create both winners and losers, stewardship requires respectful conversations among stakeholders to identify synergies and trade-offs that can then be discussed and negotiated.

Change is inevitable, but some changes are more predictable than others. Path-dependent changes with long-time lags, such as human-driven changes in climate and culture, alter variables that change slowly (slow variables) and will likely persist long into the future, providing a basis to plan for relatively predictable changes. Specific events (pulse changes), such as introduction of compulsory education, oil development, privatization of fisheries, and COVID-19, are less predictable and can trigger transformations - both good and bad. Stewardship is a framework for imagining, identifying, and changing driving forces and interventions to shape changes toward pathways that are more just and self-sustaining. It allows society to imagine and pursue pathways that may never have existed or are only memories of distant times or places. It invites experimentation rather than seeking one-size-fits-all solutions.

This special feature focuses on Arctic change. Arctic stewardship addresses primarily solutions that can be facilitated by interventions within the Arctic or that disproportionately affect the Arctic. The choice of issues to address depends on local context and stakeholder goals. Here, I describe emerging opportunities that have frequently been suggested to me by Indigenous leaders in the Alaskan communities where I work and that capture elements of the stewardship paradigm:

- The power of stories: The warming of global climate has unleashed several amplifying feedbacks such as sea-ice decline and shorter snow-covered seasons that disproportionately speed warming at high polar latitudes. Arctic observations of biophysical changes (e.g., warmer weather, more frequent and severe fires, and changes in distribution of diseases and other species) and their social consequences (e.g., rising health disparities, risks to hunters, and infrastructure damage from permafrost thaw) provide compelling narratives of the types of changes that become more frequent and disastrous as climate warms. Factually based stories about climate-change impacts are more likely to engage people's hearts and motivate empathy and action than are arguments based solely on scientific facts and logic. Several Alaskan individuals and programs (Oscar Kawagley, Alaska Native Knowledge Network, Raven's Story, Project Jukebox, StoryCorps, Grantee Stories of the Rasmuson Foundation, and many others) record and make available compelling stories about Arctic change. These programs can inspire scientists to engage in story-learning and storytelling as part of their scientific training, engagement, and outreach. Stories offer both scientists and other citizens new roles in fostering interventions that support well-being of people and nature in the Arctic and globally.

- Diffusion of adaptative actions to broader scales: Adaptation actions that provide benefits in the short and long term include strategically planned village relocations and greater use of renewable energy for heat and electricity to reduce dependence on imported diesel fuels. The larger challenge is to scale successful approaches through broad diffusion of successful adaptation. Some adaptation lessons spread informally among villages through kinship networks, regional native corporations, and community-focused agencies or NGOs. Others spread through more formalized networks such as Exchange for Local Observations and Knowledge of the Arctic (ELOKA), Alaska Arctic Observation and Knowledge Hub (AAOKH), and Local Environmental Observer Network (LEO). Research that identifies attributes of networks that have proven effective for diffusion of different adaptation actions might speed broadscale improvements in well-being. For example, when does diffusion of adaptation depend mainly on financial resources and technical capacity? When are local leadership, development of trust, and awareness of cultural context

\footnotetext{
${ }^{1}$ Institute of Arctic Biology and Dept. of Biology and Wildlife, University of Alaska Fairbanks
} 
more important? And when are larger scale institutional opportunities and constraints the primary limitation to widespread adaptation? Once the attributes needed for successful diffusion of adaptation are identified, these can be shaped by social entrepreneurs to address specific adaptation opportunities.

- Empowering local perspectives: Strengthening opportunities for local subsistence hunting and fishing enables local communities to better meet their food needs, sustain their culture, and strengthen their connections to the nature that supports them. Village-based Regional Advisory Councils provide advisory input but lack the decision-making authority that would enable rural communities to influence government subsistence management boards. In contrast, the Yukon River Intertribal Fish Commission provides a venue for community input to decision making regarding the Yukon River's king salmon fishery. Empowering local groups with greater decision-making authority would increase the likelihood of meeting rural subsistence needs and reduce the dependence of these communities on government subsidies. Public acceptance in large urban centers of the validity of rural subsistence priorities also requires identification of areas where city dwellers could hunt with minimal impact on rural communities. A starting point for fact-based discussions might identify areas with over-abundance of game (e.g., peri-urban areas and recent anthropogenic wildfires) and the relative reliance of different groups of hunters on river, road, and airplane access. These discussions will inevitably be contentious and will benefit from respectful sharing of goals, values, needs, and opportunities, as well as a deep understanding of how best to navigate contentious discussions. These are critical elements of stewardship.

- Building food security and social cohesion: Alaska has, on average, about a five-day supply of food within its borders. Encouragement of local gardening, farmers' markets, and community-supported agriculture enables people to raise their own food or buy local, seasonal food directly from farmers. These opportunities will likely increase in many northern places as climate warms. In addition, individual American consumers throw away $40 \%$ of the food they buy. Public education to reduce food waste and to teach effective gardening techniques could improve local food security and foster cultural awareness of people for the nature on which they depend through gardening and harvest of wild berries and other foods. Food-sharing also connects people culturally, especially in small Indigenous communities. Similarly, potlucks bring friends and colleagues together in more urban settings. Community celebrations, meetings of faith communities, soup kitchens, and other programs provide venues and infrastructure for broader food sharing across economic and social groups. These efforts could enhance community cohesion and meet the needs of vulnerable people if this food sharing is viewed as an opportunity to build social ties as well as a way to meet nutritional needs.

- Reshaping regional economies: As catastrophic wildfires and floods fuel public concern about environmental change, both private citizens and banks are divesting from fossil-fuel companies that contribute to climate warming. For example, several major banks have divested from Arctic oil development. If these trends continue and are supported by a shift of government subsidies from fossil fuels to renewable energy, Alaska could have a smoother transition away from fossil fuels in a not-too-distant future-if global society comes to view these fuels as an unacceptable risk to climate. Many oil companies already have renewable energy portfolios, positioning them to transition smoothly to energy provision through renewable energy.

- Revitalizing Indigenous languages: The proportion of Alaska Native people who speak their Indigenous language has declined over the past century. Language revitalization by learning from elders or even from second-language speakers is difficult but has contributed substantially to cultural integrity, identity, and pride in many Alaskan communities. Examples include the Tanan Ch'at'oh Gwich'in language nest, the Igiugig mentor/apprentice program for language revitalization, the Alaska Native Language Archive at UAF's Rasmuson Library, which houses decades of language documentation, and the Alaska Native Language Center, which is deeply involved in language documentation and teaching. The main challenge is to scale these efforts regionally by sharing language learning among remote rural communities that are often connected by kinship, social media, and other social networks.

Many transformative solutions are grounded in well-recognized past patterns or current trends in slow variables that provide a plausible foundation for future planning. Each of the issues mentioned above has been successfully addressed in one place or another. The challenge is to move toward stewardship, i.e., to shape trends in slow variables for the benefit of society and the nature on which it depends, while imagining events or actions that might trigger rapid transformative changes at broader scales. In many cases, institutions at larger scales constrain or facilitate opportunities for local-scale stewardship, requiring work by policy and social entrepreneurs to link institutions and actions across scales. The Arctic Council, for example, is the leading intergovernmental forum promoting cooperation, coordination, and interaction among Arctic nations. Indigenous people from each Arctic nation are permanent participants of the Arctic Council and, in this way, link the concerns and priorities of local Indigenous groups with international policy development. Analogously, the Innuit Circumpolar Council (ICC) is a multinational Indigenous non-governmental organization with special consultative status at the United Nations. The ICC advocates for the human, cultural, political, and environmental rights of Indigenous peoples.

In summary, despite the rapid social and environmental changes occurring in the Arctic, there are many institutions, programs, and opportunities to foster transformative change toward sustainability through Arctic stewardship.

Responses to this article can be read online at: https://www.ecologyandsociety.org/issues/responses. php/12499 
Ecology and Society 26(3): 15

\section{LITERATURE CITED}

Chapin, F. S., III. 2020. Grassroots stewardship: sustainability within our reach. Oxford University Press, New York, New York, USA. https://doi.org/10.1093/oso/9780190081195.001.0001 